\title{
Trajetos com Jesús (e para além): autoanálise da pesquisa dos usos sociais da mídia
}

\section{Veneza Mayora Ronsini}

Doutora; Universidade Federal de Santa Maria, Santa Maria, RS, Brasil

venezar@gmail.com

\section{Resumo}

Começando pelo título, "além" é uma referência à figura con(sagrada) do intelectual que conduz a amplos voos teóricos, em contraposição à figura profana do homem Jesús. Além significa, igualmente, o avanço da minha trajetória em direção a posições fronteiriças à Teoria das Mediações de MartínBarbero: dos estudos culturais latino-americanos e britânicos, à etnografia crítica da audiência, à história das mentalidades, à sociologia da reprodução e às teorias de gênero. Evidencio o impacto do especialista em Comunicação e sua metáfora do mapa noturno nas investigações sobre os usos sociais da mídia à luz da problemática das desigualdades. Finalizo com questões para pensar as dinâmicas da convergência digital e seus novos desafios para a abordagem dos conflitos culturais e políticos. A fala que segue é um palimpsesto, foi raspada e rasurada no ritmo industrial do trabalho acadêmico. Por isso, preservo as características de um texto oral elaborado sem a preocupação de referenciar todas as fontes que o embasaram, mesmo que dando nomes próprios à origem das ideias aqui sistematizadas.

\section{Palavras-chave}

Martín-Barbero. Estudos culturais. Usos sociais da mídia. Classe social. Estudos de recepção.

\section{Introdução}

A primeira parte desta fala começa com o relato de minha inserção nos estudos culturais latino-americanos, no final dos anos 1980, na Escola de Comunicações e Artes (ECA) da Universidade de São Paulo (USP), sob a orientação de Maria Immacolata Lopes e a companhia de professores, pesquisadores e alunos que fizeram parte desta história do diálogo com as ideias e os ideais do projeto intelectual do sempre amável e combativo Jesús. 
Na sequência, comento a centralidade da temática classe social na minha assimilação do projeto intelectual de Martín-Barbero e sua reflexão sobre as relações entre cultura midiática e classes trabalhadoras. Como consequência, o estudo dos usos sociais da mídia pode ser definido, a partir da Sociologia da Cultura de Bourdieu, como um "esporte de combate" e não uma área que, simplesmente, dá voz aos sujeitos. Esporte de combate que rejeita o vocabulário da consagração das teorias. Uma teoria embasada em dados e interessada em "antropofagizar" os receptores da mídia para demonstrar que podem ser fantoches ou indivíduos com alguma margem de individuação, tal como nós, na academia, reprodutores, em maior ou menor medida, dos mecanismos que oprimem ou dos que libertam. Assim como eu defino a pesquisa de recepção, é uma área de estudos que põe em evidência macro e microescalas, instituições, sujeitos e assujeitados para a interpretação dos sentidos da mídia na construção da hegemonia. Se alguns adeptos dos estudos culturais latino-americanos de recepção focam exclusivamente na resistência ao poder econômico, político, cultural e social da mídia, podemos dizer que estão cometendo uma simplificação. 0 mesmo debate surge agora: os meios digitais são nossa renovada fonte de esperança ou representam o ápice do controle da racionalidade técnica? Pelo menos nos estudos de vertente gramsciana, pensamos que as tecnologias de informação e de comunicação favorecem formas de emancipação e são incubadoras de opressão (MATTELART, 2017, p. 19).

\section{Trajetos com mestres, colegas e alunos}

A trajetória pessoal na academia está vinculada ao início da disseminação do pensamento de Martín-Barbero no Brasil graças ao curso de Metodologia da Pesquisa ministrado por Immacolata Lopes no primeiro semestre de 1989, na Escola de Comunicações e Artes da Universidade de São Paulo. A qualidade do ensino, aliada ao clima cultural da cidade, eram fomento para acolher as ideias vanguardistas do autor. Nas disciplinas cursadas na ECA, foram marcantes Aloísio Lopes, com sua história da técnica e da tecnologia, e Cremilda Medina, com a mistura de Jornalismo e prosa literária. Na Sociologia e na Antropologia da Faculdade de Filosofia, Letras e Ciências Humanas (FFLCH), sou grata a Sergio Miceli, Roberto Cardoso de Oliveira, José Guilherme C. Magnani, Ruth Cardoso, Karl Monsma e Sedi Hirano.

A abertura para a interdisciplinaridade eu devo à Immacolata: da Sociologia da Cultura à Sociologia Histórica, de Weber a Marx; da Filosofia Hermenêutica à Antropologia 
Urbana, passando pela Universidade Estadual de Campinas (Unicamp), com Renato Ortiz. A figura de Milton Santos, primeiro conhecida em De los medios, eu vi ao vivo e a cores na cafeteria da História e da Geografia com seu sorriso terno e suas palavras afetuosas. Sua obra foi muito marcante quando escrevi Mercadores de sentido (RONSINI, 2007).

Com os colegas da ECA - Salett Tauk dos Santos, Angelo Brás Callou, Maria Luiza Nóbrega, José Maximiliano Henriquez Sandoval (Max), Nilda Jacks, Ana Carolina Escosteguy, Jiani Bonin e Alberto Efendy Maldonado - eu pertencia a uma comunidade, sem celulares e redes sociais, que incluía uma conexão entre Pernambuco, Paraíba, Bahia e Rio Grande do Sul, ou nas palavras de Ângelo Brás Callou (professor da rural de Pernambuco), o sertão com o sertão dos pampas. Na época, especialmente, eu, Salett e Brás tínhamos vínculos com um trabalho interessado nas relações entre comunicação e meio rural. História de sincronicidades, de acordo com a psicanálise de Jung, e não de acasos: de viver o mesmo tempo e sentir coisas semelhantes. Martín-Barbero era pauta dos assuntos mais prosaicos, mesmo daqueles que entretinham nossas viagens da USP ao centro da cidade, como a experiência de Max no aeroporto ao embarcar para Salvador e de lá para Jequié: aceitou levar uma encomenda para um parente de seu vizinho e o sujeito aparece com um aparelho de televisão. No seu retorno, trouxe o bolo de Jequié para entregar como recompensa pelo televisor. Ele era o carregador dos agrados e dos bens de consumo entre as famílias. Aí está a importância do consumo como forma de comunicação e dos laços primordiais da família descritos por Barbero.

Immacolata deu as pistas para navegar no seu mapa noturno. Ela foi a metodologia do dia para enfrentar a anarquia da noite. Em 1989, o estranhamento e o encantamento com De los medios a la mediaciones (MARTÍN-BARBERO, 1987) foi imediato. 0 primeiro encanto foi com sua visão da cultura popular e da história vinda de baixo, com a noção de classe social e de experiência: pela combinação interdisciplinar para dar conta de uma totalidade, mesmo que focada no tempo presente que evoca a memória de um passado transmitido pela modernidade da mídia, da tradição familiar e do bairro popular.

Foi Martín-Barbero quem alertou sobre a vitalidade da noção de classe social, enquanto, por longos anos, confundiu-se seu valor heurístico com o fracasso dos projetos de esquerda, dos regimes totalitários estatistas, da revolução da classe operária com a noção (imprecisa) de classe e a discussão (necessária) da desigualdade econômica no continente latino-americano, em um país que figura entre os 10 mais desiguais do mundo. 
As disputas intelectuais estão sempre fundadas em pressupostos políticos e econômicos e não seguem somente lógicas epistêmicas. Por um lado, a visão dominante no campo comunicacional tem "[...] fatalmente isolado sua teoria e prática do desenvolvimento geral das ciências sociais, o que encoraja em seus profissionais a ilusão de uma autonomia empírica e teórica." (HALL, 2016, p. 35). Por outro, o positivismo aprova o que pode ser generalizado. Minha dissertação foi recusada para publicação duas vezes: por um periódico, no início da década de 1990, porque era Antropologia e não Comunicação e, depois, agraciada com o prêmio nacional da Sociedade Brasileira de Estudos Interdisciplinares da Comunicação (Intercom). Após, uma editora não aceitou publicar em parceria porque se tratava de um limitado estudo de importância local, já que falava sobre as transformações sociais e culturais, mediadas pelos meios de comunicação, em uma comunidade camponesa na região da Quarta Colônia de imigração italiana no Rio Grande do Sul. Por absoluta falta de tempo, eu só publiquei um artigo ínfimo na revista da Intercom e segui em frente. Mas fica a sensação de que poderia ter circulado mais, pois eu fiquei cinco anos me dedicando a essa investigação que, pelo menos, pode funcionar ainda hoje como modelo para os estudantes que desejem se arriscar na pesquisa empírica de recepção, saindo dos muros da academia e encontrando a vida das pessoas comuns.

Os estudantes de mestrado e doutorado, por seu turno, reforçaram ainda mais o interesse anárquico por novas frentes de trabalho, mantendo o eixo das clivagens de classe sempre constante. Renata Silva, Laura Wöttrich e Lirian Sifuentes me empurraram para as relações de gênero; Sandra Depexe para a circulação das telenovelas no twitter; Filipe Santos e Milena Cruz para a publicidade e gênero; Flora Dutra para a sociabilidade mediada pelos smartphones; Fernanda Scherer para consumo de mídia e transexualidade; Otávio Chagas para telenovelas e as masculinidades; Camila Marques para o consumo de moda, e Gustavo Dhein para as telenovelas e classe em Cuba.

Outro fracasso, que considero fundamental para entender o meu apreço "orgânico" pela revolta que Martín-Barbero irradia nos seus textos, foram as demissões na minha breve carreira de jornalista no jornal impresso e na televisão por insubordinação à ideologia das empresas: por um lado, pelo sexismo, incompatível com minhas leituras, autodidáticas, como estudante de Jornalismo e jornalista na década de 1980, de A origem da família, da propriedade privada e do Estado (ENGELS, 1984) e Sexo e temperamento (MEAD, 1979); do feminismo de Rose Marie Muraro e de Simone de Beauvoir, da Psicologia Antropológica de Malvina Muszkat e Zelita Seabra, das perspectivas sociais e antropológicas das relações de 
gênero; por outro, pela subordinação das empresas a partidos políticos e aos financiamentos publicitários.

E aqui vale digressão sobre a liberdade que temos (ou não) nas instituições universitárias diante da constante ameaça do predomínio das leis do mercado no ensino e na pesquisa, além da publicidade pessoal que fazemos nas redes sociais. Não é novidade a constatação de que Instagram e Facebook são plataformas de construção do perfil individual e profissional, assim como os meios de informação e de comunicação são recursos para nossa autoimagem e nossa visão de mundo. Em uma manhã do mês de outubro 2017, assisto, no Bom dia Rio Grande, à matéria jornalística sobre o evento que reunia acadêmicos, empresários e marqueteiros no lançamento do Ahead RBS (ou traduzindo, Avante RBS!): estratégia de marketing do grupo interessada em gerenciar a forma de comunicação das empresas com seus públicos. Entre os palestrantes, um executivo do Santander e outro do Mac Donalds falando sobre o respeito à diversidade e a conclusão de que a manifestação de preconceitos é nociva para a relação empresa-público. 0 executivo da rede dizia que a comunicação pode ser fast-food e, ao mesmo tempo, boa. Coisa que ninguém duvida, pela analogia promissora entre alimentos e o marketing como alimento para o lucro.

A visão sobre a eficiência da publicidade e das leis do marketing utilizada nas empresas é aplicada não apenas nas empresas de comunicação (SHARP, 2017), que vendem informação e entretenimento, mas também já foi incorporada na vida privada dos habitantes das cidades e, talvez em menor medida, do campo. Não importa a diferença entre as marcas, o que importa é que todas substituam "o psicologismo barato", que domina a área do marketing (palavras textuais do professor Sharp da University of South Australia, diretor de um Instituto nesta universidade), pela visão científica de professores de Ciências do Marketing interessados no comportamento de compra e crescimento de marca. Evidentemente, o elemento básico desta ciência é modelo matemático e sua teoria "verdadeiramente científica" (SHARP, 2017, p. 17) que persegue a generalização empírica, "sistematizada em leis" como a do monopólio natural (maior participação no mercado, maior número de compradores). Este instituto entende que o consumo é movido por impulsos, mas que isto não é importante, porque as regularidades observadas entre os compradores são surpreendentes. Não importa qual é a marca e a fidelidade à marca, já que grandes corporações estão interessadas no volume do que é comprado. Então, fico me perguntando qual é realmente a liberdade do consumidor cidadão, do interator, interagente, 
produtor, prossumer, comunicante e todo o vocabulário que está sendo formulado para entender a transformação da audiência e do receptor neste cenário digital e neoliberal.

0 trajeto com as questões culturais, políticas e comunicacionais levantadas por Martín-Barbero assumiu, hoje, feições (melo)dramáticas, visto que nossa autonomia como mediadores culturais nas "indústrias criativas" e nas universidades encontra-se ameaçada pela tentativa de desmantelamento, sempre vigente, do exercício livre do pensamento em função da manutenção dos privilégios econômicos de uma minoria. Quando terminou de escrever Contribuição à crítica da economia política, publicada em 1859, Marx (1977) proclamou que escreveu o "desgraçado" do manuscrito sobre o dinheiro com muita falta dele. Guardadas às proporções relativas ao tempo histórico e dependendo do nosso tema e objeto de pesquisa, padecemos da mesma falta de paz do autor que se deve não apenas às contingências materiais, mas ao desconforto moral diante da conformidade acadêmica com a gênese das desigualdades, a saber, com a exploração econômica combinada à sua reprodução cultural.

Para que servem nossos desgraçados manuscritos (que, até o momento, para a maior parte de nós, continuam sendo redigidos com as mãos)? Essa pergunta vem de MartínBarbero, dos meus mentores, colegas, amigos, alunos. Origina-se de um grupo de pessoas vivendo o período histórico, contra e a favor das teorias, refletindo sobre a condição humana no corpo a corpo da pesquisa empírica.

Uma resposta convincente e sintética para a pergunta é a da intelectual norteamericana Suzan Sontag (2003). Ao criticar Guy Debord e Jean Baudrillard, a escritora questiona a tese pós-moderna sobre a erosão do sentido de realidade e, ao fazê-lo, também apresenta um argumento alentador à pesquisa de recepção porque, para Sontag (2003) e para nós existe uma realidade para além do sentido e da tentativa de enfraquecimento da própria realidade. Existem bilhões de espectadores que estão longe de se sentirem impassíveis às imagens catastróficas da guerra, da devastação, da violência e do terror. E, por acréscimo, entender a realidade somente como espetáculo tem como consequência chancelar a apatia política e sacramentar a eterna denúncia do totalitarismo da civilização da imagem contra a razão. 0 problema não está nas imagens, porque elas podem ser outra modalidade de apreensão cognitiva que emociona e faz pensar. A dissociação entre emoções e pensamento, sabemos, não é somente um paradigma, é a visão dominante sobre as classes populares, as mulheres, as minorias sexuais, os negros, os índios, as crianças, os jovens. 


\section{As classes trabalhadoras ou a história vista de baixo}

Os termos-chave do autor - comunicação, cultura e poder - no clássico De los medios a las mediaciones (MARTÍN-BARBERO, 1987) são retomados para pensar as culturas das classes populares (e suas relações com outras classes), incluindo: (1) as pesquisas realizadas na década de 1990 com o campesinato e, na sequência, com migrantes rurais estabelecidos na periferia urbana; (2) duas investigações na década de 2000 com jovens das classes trabalhadora e média ligados a movimentos culturais, subculturas ou estilos juvenis, além do estudo comparativo com jovens do Ensino Médio da elite, classe média e classe popular sobre as leituras da desigualdade e da pobreza; (3) pesquisa do consumo e recepção das telenovelas com mulheres heterossexuais de diferentes gerações - da elite e das classes trabalhadoras - e a produção de uma feminilidade de classe. Finalmente, a continuidade desse projeto anterior, com o aprofundamento teórico sobre as relações entre usos da telenovela e o consumo midiático e a extração de capital simbólico pelas mulheres pobres.

A epistemologia comum nesse trajeto da pesquisa de recepção é a formulação sem fórmulas para capturar tempo e espaço do consumo, conjugando a perspectiva da história das mentalidades e a perspectiva antropológica. Apreender somente o tempo presente pode significar ocultar a conexão com as apropriações pretéritas das tecnologias ao longo de gerações, privilegiando as apropriações espaciais. Esconde-se o que o espaço tem de tempo, isto é, esconde-se o lugar. As mutações longas da sociedade de consumo só podem ser bem compreendidas com a voz do receptor de hoje e das ressonâncias nela da memória social. Fatos, conjunturas e estruturas sociais estão interligados às mentalidades que são subjetivas e objetivas, produtos da ordem reguladora das atividades conjuntas dos homens no espaço.

A ordem do tempo, ensina o filósofo Elias Canetti (1995, p. 398), é “[...] o mais nobre atributo de toda dominação.". 0 tempo curto da recepção e do consumo foi tecido com os fios do tempo longo: da sociedade de "massas", da sociedade de classes, da inércia das mentalidades (VOVELLE, 1990). As mudanças recentes que comunicólogos como MartínBarbero, Muniz Sodré e Guillermo Orozco Gómez apontam como estruturais ${ }^{1}$ necessitam, portanto, ser pensadas como formações sociais (ou a sociedade no tempo) para a captura de experiências, virtuais e não virtuais. Mas não é só isso, porque os tempos se sobrepõem como já apontou Renato Ortiz (1988) em A moderna tradição brasileira.

\footnotetext{
${ }^{1}$ Na coletânea organizada por Dênis de Moraes (2010) sobre a sociedade midiatizada.
} 
Espaço e tempo estão no meu horizonte, com a ressalva que trabalhar com a mudança temporal é um exercício limitado, nas minhas investigações, às escavações das vozes dos informantes que ganham sentido mais amplo (isto é, no espaço) e longo (isto é, no tempo) com as teorias comunicacionais, sociais, históricas (dos registros das mentalidades), com a metodologia crítica da audiência e os retratos sociológicos individuais de Lahire (2004). Mesmo que as relações de poder releguem os trabalhadores - as massas, as audiências - ao grupo de pessoas "sem história" (BURKE, 2000, p. 85).

A perspectiva dos usos sociais da mídia continua sendo uma história curta, calcada no presente que recorda o passado das gerações anteriores: às vezes longe no tempo, no século XIX, na leva das migrações da Itália para a Quarta Colônia Italiana no Rio Grande do Sul. Significa recortar o objeto teoricamente/empiricamente ao espaço para também captar - através da trajetória do sujeito ou ator social - a densidade histórica do lugar. As instituições da família, da escola, do trabalho ou a sociabilidade nas redes de vizinhança, no bairro e na cidade/campo, evidenciam o peso das heranças autoritárias do passado histórico e as mudanças através de gerações. Nossa meta pode ser nos tornamos arqueólogos da comunicação viva no presente, analogamente a áreas do conhecimento como a Arqueologia brasileira - que se tornou, a partir dos anos 1980, arqueologia interpretativa, ou a ciência histórica e cultural das sociedades vivas (com margem de imprecisão, presumo) - ou a história tradicional que, como ciência dos fatos e dos feitos, se transformou em história cultural ou história das mentalidades.

A ideia de determinação (WILLIAMS, 1991) de classe, no projeto de investigação em andamento, é pensada em termos de representações e formas subjetivas que organizam as identidades femininas e suas práticas cotidianas, articulando-se com as narrativas das telenovelas na reprodução das desigualdades. A centralidade da cultura ou a autonomia relativa da cultura, para mim, significa que cultura e economia são indissociáveis. Leia-se cultura como ideologia e contraideologia (BOSI, 2010) ou, na acepção de García Canclini (1997), cultura e ideologia.

A predominância do econômico na constituição da estrutura e das formações sociais é razão para intensos debates nas Ciências Sociais e Humanas, porém fui e sou motivada pelas perspectivas de Raymond Williams, Norbert Elias e Pierre Bourdieu, que têm em comum o pressuposto de que as pressões e os limites exercidos pelo econômico estão em articulação com o campo cultural. 0 conceito de gênero, da historiadora feminista Joan Scott (1986), parece em sintonia com o materialismo dos três pensadores que procederam a uma 
revisão do princípio básico da teoria marxista da cultura para caracterizar os aspectos morais e materiais da existência humana no capitalismo.

Como me disse Roger Silverstone, na London School of Economics, pensar o conceito e a questão da determinação é condição para fazer ciência e não podemos abdicar desta, mesmo diante de uma disputa sobre a própria noção de ciência, dos seus princípios e finalidades (MARTINO, 2007).

0 modo como Raymond Williams entende a relação entre base e superestrutura contribui para, por um lado, não abandonarmos essa pretensão; por outro, para analisar a produção cultural como social e material. Assim, por exemplo, a literatura, como produção de sentido, em $O$ campo e a cidade, está em tensão com o conceito de literatura como registro, expressão ou dramatização de valores porque a forma literária é contrastada com a história (WILLIAMS, 1990). Em segundo lugar, Williams (1980) desafia a noção de que a literatura é "apenas convenção", mas um meio de produção analisado com base nas condições históricas de sua produção. Isto é, ele combate trabalhos de crítica literária que rejeitam preocupações relativas às condições de produção como sendo "historicismo" e "sociologismo".

Ao invés, ele prefere ver a literatura como convenção formal e relação social, insistindo nos aspectos da representação histórica e nas falsas representações ou mentiras interessadas em manter privilégios de classe (WILLIAMS, 1981). As convenções literárias produzem ações e relacionamentos, bem como prosa e poesia. A semelhança com a história concreta (real) não é o mais relevante porque a representação pode estar ligada a situações possíveis. As convenções mais válidas não são sempre realistas, embora, frequentemente, este seja o caso.

\section{Anotações finais}

Enfim, o modo de definição da literatura de Williams (1981) vale para a mídia de massa ou para a digital: é uma convenção produtiva, estética e socialmente, porque é uma realização que contribui com a cultura humana; é uma convenção produtiva da sociedade burguesa, desastrosamente poderosa, que restringe a liberdade humana.

Como disse Williams, existem ensinamentos centrais no marxismo que desafiam, por um lado, a noção de história como miséria e sofrimento permanentes (visão da Escola de Frankfurt); por outro, a noção de que o aumento da produtividade pela liberação das forças produtivas combate, necessariamente, a pobreza e a escassez. 0 que isso tem a ver com a 
mídia? No que diz respeito ao primeiro aspecto, certamente, a mídia não está somente ao lado da geração de miséria e sofrimento, porque deseja ampliar o número de consumidores ao máximo. Quanto ao segundo, a produtividade do capital financeiro depende e está literalmente conectada ao mercado, organizando a sociedade da informação e da comunicação. 0 poder se reformula para atender aos ditames do capital financeiro e empresarial de braços dados com o desmantelamento do Estado, e as tecnologias digitais são um de seus instrumentos.

Mesmo com o aumento exponencial da desigualdade, classe social deu lugar a novas formas de pensar as identidades: de gênero, étnico-raciais, geracionais. Politizou-se o debate em outros termos, até em termos mais palatáveis para o capital midiático-financeiro, que, ao apresentar as demandas por reconhecimento, minimiza as demandas por justiça distributiva. A crise das instituições da modernidade - trabalho, escola e política - é uma situação desnorteadora para a maioria: identidades locais são essencializadas (exóticas) no mesmo compasso da fragmentação dos referentes culturais tradicionais pela mobilidade das redes e fluxos de informação e comunicação (MARTíN-BARBERO, 2010a). Mas o autor não nos faz esquecer da contradição fundamental da convergência digital, sua potência para a interação cultural no ecossistema comunicativo (MARTÍN-BARBERO, 2010b) ou a conexão cognitiva e criativa: a convergência digital significa também a renovação do modelo de comunicabilidade unidirecional e linear da transmissão da informação ao modelo interativo da rede.

As lições de Martín-Barbero são observadas na vida privada. Quando meu filho músico administra a produção e o lançamento do seu álbum, ele demonstra que rede é também um modelo da proximidade e sinergia entre grupos e tecnologias, entre parcerias e disputas, entre tecnologias caríssimas que são copiadas para fazer frente à incrível desigualdade entre gigantes da música e os Davis da criação.

\section{Financiamento}

Pesquisa financiada com bolsa do Conselho Nacional de Desenvolvimento Científico e Tecnológico (CNPq) e estágio sênior com bolsa da Coordenação de Aperfeiçoamento de Pessoal de Nível Superior (Capes) na Nottingham Trent University, Reino Unido.

\section{Agradecimentos}

Marcos, Marina e Martim pelo imenso amor. 


\section{Referências}

BURKE, Peter. Variedades da história cultural. Rio de Janeiro: Civilização Brasileira, 2000. BOSI, Alfredo. Ideologia e contraideologia. São Paulo: Companhia das Letras, 2010.

CANETTI, Elias. Massa e poder. São Paulo: Companhia das Letras, 1995.

ENGELS, Friedrich. A origem da família, da propriedade privada e do Estado. Rio de janeiro: Civilização brasileira, 1984.

GARCIA CANCLINI, Nestor. Ideologia, cultura y poder. Buenos Aires: Universidad de Buenos Aires, 1997.

HALL, Stuart. A ideologia e a teoria da comunicação. MATRIZes, São Paulo, v. 10, n. 3, p. 33 46, set/dez. 2016.

LAHIRE, Bernard. Retratos sociológicos: disposições e variações individuais. Porto Alegre: Artmed, 2004.

MARTÍN-BARBERO, Jesús. Convergencia digital e diversidade cultural. In: MORAES, Dênis (Org.). Mutaciones de lo visible. Barcelona: Paidós, 2010b. p. 137-165.

MARTÍN-BARBERO, Jesús. De los medios a las mediaciones: comunicación, cultura y hegemonía. Barcelona: Gustavo Gili, 1987.

MARTÍN-BARBERO, Jesús. Tecnicidades, identidades, alteridades: mudanças e opacidades da comunicação no novo século. In: MORAES, Dênis (Org.). Sociedade midiatizada. Rio de Janeiro: Mauad, 2010a. p. 51-79.

MARTINO, Luiz C. Uma questão prévia: existem teorias da comunicação? In: MARTINO, Luiz C. (Org.). Teorias da comunicação: muitas ou poucas? Cotia: Ateliê Editorial, 2007. p. 1342.

MARX, Karl. Contribuição à crítica da economia política. São Paulo: Martins Fontes, 1977.

MATTELART, Armand. Por una crítica de los sistemas socio-técnicos de control. In: SALADRIGAS, Hilda; OLIVERA, Dasniel; PAZ, Sarah (Coord.). Información y comunicación desde el sur: economía política, cultura y pensamiento crítico. La Laguna: Latina, 2017. p. 19-44. (Cuadernos Artesanos de Comunicación).

MEAD, Margaret. Sexo e temperamento. São Paulo: Perspectiva, 1979.

MORAES, Dênis (Org.). Sociedade midiatizada. Rio de Janeiro: Mauad, 2010.

ORTIZ, Renato. A moderna tradição brasileira. São Paulo: Brasiliense, 1988.

RONSINI, Veneza Mayora. Mercadores de sentido: consumo de mídia e identidades juvenis. Porto Alegre: Sulina, 2007.

SCOTT, Joan W. Gender: a useful category of historical analyses. The American Historical Review, Bloomington, v. 91, n. 5, p. 1053-1075, Dec. 1986. 
SONTAG, Susan. Diante da dor dos outros. São Paulo: Cia das Letras, 2003.

SHARP, Byron. Como as marcas crescem. São Paulo: Globo, 2017.

VOVELLE, Michel. A história e a longa duração. In: LE GOFF, Jacques. A história nova. São Paulo: Martins Fontes, 1990. p. 25-64.

WILLIAMS, Raymond. Base and superstructure in marxist cultural theory. In: MUKERJI, Chandra; SCHUDSON, Michael (Ed.). Rethinking popular culture: contemporary perspectives in cultural studies. Berkeley: University of California Press, 1991. p. 414-416.

WILLIAMS, Raymond. Marxismo y literatura. Barcelona: Península, 1980.

WILLIAMS, Raymond. 0 campo e a cidade: na história e na literatura. São Paulo: Companhia das Letras, 1990.

WILLIAMS, Raymond. Politics and letters: interview with New Left Review. London: Verso, 1981.

\title{
Journey with Jesús (and beyond): self- analysis of social media research
}

\begin{abstract}
Beginning with the title, "beyond" is a reference to the (sacred) figure of the intellectual leading to broad theoretical flights, as opposed to the profane figure of the man Jesús. Also, the progress of my trajectory towards the frontiers for MartínBarbero's Theory of Mediations: from Latin American and British cultural studies to audience critical ethnography, history of mentalities, sociology of reproduction and gender theories. To show the impact of the expertise in Communication and its metaphors of the night map in the investigations on the uses of the media taking into account the problematic of the inequalities. I conclude proposing questions about the dynamics of digital convergence and its new challenges for addressing cultural and political conflicts. The following speech is a palimpsest, was scraped and washed off in the industrial rhythm of academic work. For this reason, I preserve the oral character of this text drawn up without the concern of referring all the sources that supported it, even if giving proper names to the origin of the ideas systematized here.
\end{abstract}

\section{Keywords}

Martín-Barbero. Cultural studies. Social uses of the media.

Social class. Reception studies.

Recebido em 16/03/2018

Aceito em 13/05/2018 